\title{
A Robotic Automated Vegetable Making Machine
}

\author{
Sukhmeet Singh, Paras Chawla, Ishbir Singh
}

\begin{abstract}
The process of cooking by robot has been drawing the attention of professionals and researchers. But not many researches have been done on this topic all over the world. The main purpose of this paper is to find the gaps from the systematic review on cooking robot. This systematic review was conducted according to PRISMA guidelines. For evidence acquisition we searched IEEE, Science Direct and Web of Science libraries. The last search was performed on March 29, 2019 by us. We identified 3416 publications from initial search, out of which 19 publications were retrieved. Out of these 19 publications 10 publications were excluded due to duplicate publication. But only 6 publications are of our interest.
\end{abstract}

Index Terms: Robot, cook, dish

\section{INTRODUCTION}

In all over the world mostly people take their meals three times i.e., breakfast, lunch and dinner. As the geographical area changes the weather conditions also changes. With the change in weather the type of vegetables, herbs and fruits changes. Due to this, types of food dishes also changes. For example in India, people who are living near coastal areas depend upon seafood like fishes, crabs as compared to the people who are living in plain areas mostly depend upon vegetables. In this modern era all people especially ladies want that cooking should be completed quickly and automatically. In order to complete the cooking work developers start developing robot that help us in cooking. First challenge that robot should recognize the objects which are used in kitchen. For this IC labeled tags were applied on coffee jar, tea jar etc. so that robot could recognize it easily [1]. While cooking the food in pot we have to stir the food continuously or after regular intervals of time. So a trajectory planning method was adopted to make food in pot[2]. In some cases the movement of pot is necessary while making food. The movement of pot can be circular motion, linear motion or it can be slight turn in forward, backward, left or right direction[3]. Before preparing the food the first main part is to cut the vegetables. For cutting the vegetables the motion of both the hands was used. When one hand is moving the vegetable then the second hand is cutting that vegetable by knife[4]. In next step robot will put all the vegetables and spices into the pot. While putting all the ingredients in any pot it is very necessary to take care that all the material should be put into the pot i.e. material should not fall outside the pot [5].

Revised Manuscript Received on September 10, 2019.

Sukhmeet Singh, Chandigarh University, Mohali, India

Paras Chawla, Chandigarh University, Mohali, India

Ishbir Singh, Chandigarh University, Mohali, India

\section{RESEARCH METHODOLOGY}

The table shows the complete detail of research papers year wise. In first and second columns author's name and year of publication is mentioned. In third column country name is mentioned in which the research work is done. In fourth column objective is mentioned. Fifth column mentions the type of dishes which will be cooked. Last column shows the type of operation which we have to perform in order to prepare the dish.

\begin{tabular}{|l|c|c|c|c|c|}
\hline Author & Year & Country & $\begin{array}{c}\text { Objective } \\
\text { (to prepare) }\end{array}$ & Dish & Operation \\
\hline $\begin{array}{l}\text { W. X. Yan } e l \\
\text { al }\end{array}$ & 2007 & China & Food & Chinese & Fry \\
\hline $\begin{array}{l}\text { K. Yamazaki } \\
\text { el al }\end{array}$ & 2010 & China & Vegetable & Vegetable & Cut, Peal \\
\hline $\begin{array}{l}\text { J. Wei } \\
\text { el al }\end{array}$ & 2012 & & Design & Bread & Smile \\
\hline $\begin{array}{l}\text { Y. Matsushima } \\
\text { el al }\end{array}$ & 2013 & Japan & Food & Japanese & Cut, Boil, Fry \\
\hline $\begin{array}{l}\text { N. Yoshida } \\
\text { el al }\end{array}$ & 2013 & Japan & Egg & Egg & Break \\
\hline $\begin{array}{l}\text { M. Sutiono } \\
\text { el al }\end{array}$ & 2016 & Indonesia & Rice & Rice & Boil \\
\hline
\end{tabular}

\section{LITERATURE REVIEW}

After 2007 a good amount of research work was done regarding cooking in China. W. X. Yal et al. prepared Chinese dishes namely Jiangsu, Sichuan, and Shandong etc. The robot prepared these dishes by frying[6].To make salad first we have peel and cut the vegetable. In 2010 many experiments were done on vegetables for preparing salad by Kimitoshi YAMAZAKI et al. In these experiments vegetables were cut by knife and peeled by using peeler [7]. When we go to restaurant or hotel for eating food, we are very much attracted by food decoration. In cafeteria, chef makes design of smiley or mentions the name on the coffee. On the same concept Jun Wei et al. make heart and smiley on the piece of the bread. This type of experiment was done in order to increase the attractiveness and to entertain kids [8]. In 2013 Yukiko Matsushima et al. proposed four Japanese dishes which can be prepared at home by taking guidance from tablet [9].In $2013 \mathrm{~N}$. Yoshida et al. tried to break an egg by the edge of pan. They used robot arm to crack the egg. After cracking all the contents were collected inside the pan[10]. In 2016 Michael Sutiono et al. from Indonesia gave the concept of rice cooker. This rice cooker was called as smart rice cooker. It boiled the rice[11]. 


\section{SUMMARY OF LITERATURE REVIEW AND RESEARCH GAP}

Many types of function were done on making dishes like boiling, frying, cutting and pealing. Egg was also put in pan after breaking it. All the experiments were done on making Chines, Japanese and Indonesian dishes as the authors belongs to China, Japan and Indonesia. But in all these dishes no Indian dish is discussed. There are many vegetables like potato, brinjal, cauliflower, beans, bottle guard, bitter gourd, peas, mix vegetables etc. and many types of pulses which are daily prepared in an Indian kitchen, on which no cooking robot has been developed.

\section{LIMITATION AND CONCLUSION}

The literature review represents the summary of different types of dishes prepared by different robots. But in these dishes temperature is not mentioned. When the dishes are boiled, up to how much temperature the robot or material of the robot can bear the heat even at high flame. In this modern era we want that all our daily household chores should be done quickly and automatically. Almost no work has been done to prepare India dish by cooking robot. We Indians have to do lot of experiments to prepare optimum cooking robot.

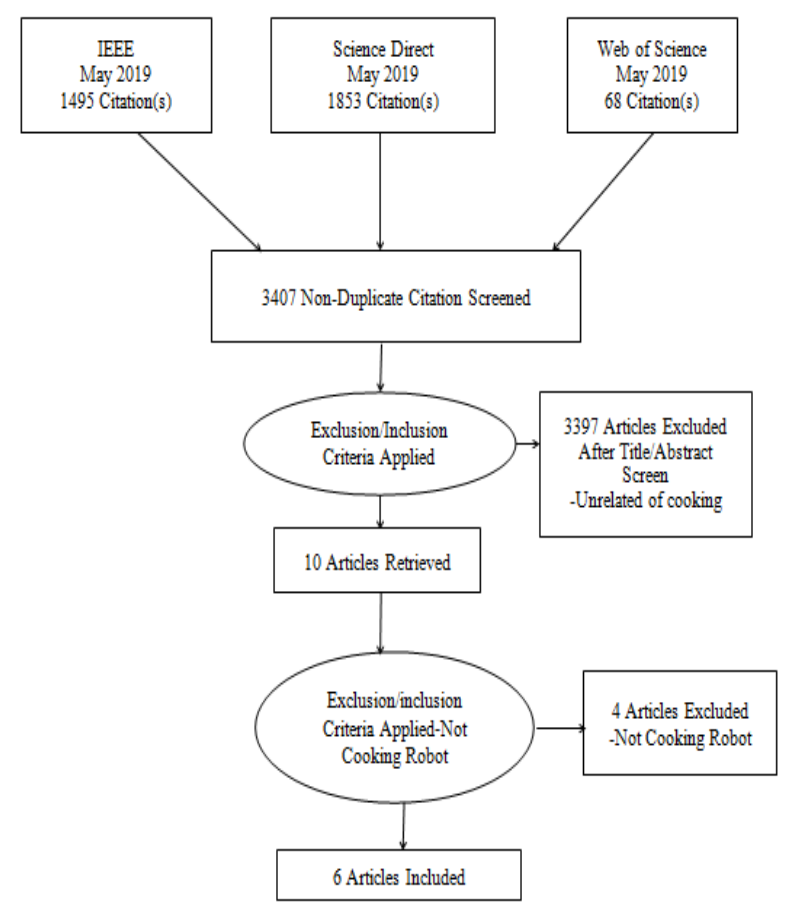

\section{REFERENCES}

[1] Y. Nakauchi, T. Fukuda, K. Noguchi, and T. Matsubara, "Intelligent kitchen: Cooking support by LCD and mobile robot with IC-labeled objects," in 2005 IEEE/RSJ INTERNATIONAL CONFERENCE ON INTELLIGENT ROBOTS AND SYSTEMS, VOLS 1-4, 2005, pp. 2464-2469.

[2] H. Rong, X. Dai, and X. Liu, "Trajectory Planning Method of the Pot in Cooking Robot," in 2010 2ND INTERNATIONAL ASIA CONFERENCE ON INFORMATICS IN CONTROL, AUTOMATION AND ROBOTICS (CAR 2010), VOL 1, 2010, pp. 129-132.

[3] Y. Chen, Z. Deng, and B. Li, "Numerical simulations of motion behaviors of pan mechanism in a cooking robot with granular cuisine," $J$. Mech. Sci. Technol., vol. 25, no. 3, pp. 803-808, Mar. 2011.
[4] S. Taki, K. Fujimoto, H. Osaki, Y. Munesawa, and Y. Kajihara, "Generating method of procedure for cutting ingredient by cooking robot," in ICIM' 2004: PROCEEDINGS OF THE SEVENTH INTERNATIONAL CONFERENCE ON INDUSTRIAL MANAGEMENT, 2004, pp. 32-37.

[5] D. Sakamoto, Y. Sugiura, M. Inami, and T. Igarashi, "Graphical Instruction for Home Robots," 2016.

[6] W.X. Yan et al., "A novel automatic cooking robot for Chinese dishes," Robotica, vol. 25, no. 4, pp. 445-450, 2007.

[7] K. Yamazaki, Y. Watanabe, K. Nagahama, K. Okada, and M. Inaba, "Recognition and Manipulation Integration for a Daily Assistive Robot Working on Kitchen Environments," pp. 196-201, 2010.

[8] J. Wei and A. D. Cheok, "Foodie: Play with Your Food Promote Interaction and Fun with Edible Interface," vol. 58, no. 2, pp. 178-183, 2012 .

[9] Y. Matsushima, N. Funabiki, T. Okada, T. Nakanishi, and K Watanabe, "A Cooking Guidance Function on Android Tablet for Homemade Cooking Assistance System,” pp. 249-254, 2013.

[10] N. Yoshida, T. Yoshimi, M. Mizukawa, and Y. Ando, "A study of egg breaking motion by single robot arm," in 2013 32ND CHINESE CONTROL CONFERENCE (CCC), 2013, pp. 6057-6062.

[11] M. Sutiono, H. Nugroho, and K. Karyono, “Appliance Hub : A Wireless Communication System for Smart Devices ( Case Study: Smart Rice Cooker )," no. 978, pp. 125-130, 2016.

\section{Authors Profile}

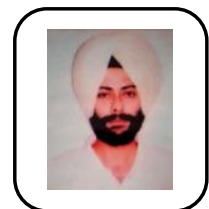

Sukhmeet Singh, Technology Education and Research Integrated Institution, Kurukshetra, India

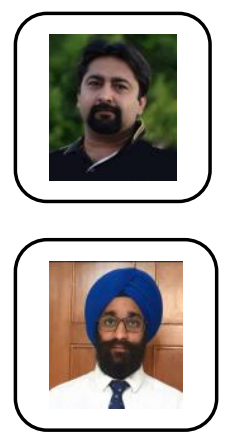

Paras Chawla, Ph.D. in ECE, Chandigarh University, Mohali, India

Ishbir Singh, Ph.D. in ME. Chandigarh University, Mohali, India 